Gabriel Furmuzachi

\title{
REASON AND NATURE - A CANADIAN PERSPECTIVE
}

In the following essay, I will try to analyze the relationship between reason and nature, as it appears in the work of Canadian philosopher, William Lyall.

This essay is developed in two dimensions: the first sketches what I believe to be an interesting account of the above stated relationship, which Lyall elaborates and presents through his work "Intellect, the Emotions and the Moral Nature” and the second is concerned with qualifying this account from the stand point of the authors of "The Faces of Reason - An Essay on Philosophy and Culture in English Canada 1850-1950”, Leslie Armour and Elizabeth Trott. The reason for doing this is the following: in their book, Armour and Trott put on the foundation of the concept of Canadian philosophy a special use of reason, namely - an accomodationist one. In the same book, when analyzing Lyall's contribution to philosophy, the authors conclude with the fact that he was not an original philosopher and that his work is merely a conglomeration of foreign ideas. But this is an unfair dismissal. If they are correct when they proclaim the accomodationist use of reason, then they should consider Lyall's contribution as nothing else but a beautiful example for their theory.

William Lyall taught philosophy at the Free Church College, in Halifax. His ideas were developed in close connection to the Scottish philosophy of common sense. He studied thoroughly Locke, Reid and Carlyle as well as Descartes, Kant, Fichte. His way of dealing with things can be reduced to sorting and clarifying intuitions in order to integrate them into a coherent pattern. Once at this point, he re-examines the situation to see what new intuitions come to light. Lyall “...tends to state a thesis, and then qualify it, qualify it some more, and then qualify it still further. After several pages of such qualifications we discover that he does not hold the original thesis at all.”(J.D.Rabb - Canadian Philosophy at Lakehead: The Silver Jubilee Lecture in Philosophy). Let us take a look at the way he talks about the essential qualities. He starts by saying that "we have thus, then, arrived at the essential properties of matter. These are extension, divisibility, solidity or fluidity, hardness or softness, and figure.” - Intellect, the Emotions and the Moral Nature, p. 47. Then he clearly distinguishes between these essential, or primary qualities and the secondary qualities such as color, sound, fragrance, heat or cold, sweetness or bitterness which "do not enter into our idea of matter". There is nothing surprising up to here. Other philosophers worked with this distinction in the European philosophical tradition. And, when one would expect that he is happy with the framework, he goes further, turning to the 
thought of his former teacher, the Scottish common sense philosopher Thomas Brown. With Brown's help, he manages to change the 'bundle' of properties with which he started: 'According to Dr. Brown, himself, extension and resistance are the only two qualities which can invariably be predicated about matter; for figure and magnitude are modifications of extension, -- as solidity and fluidity, hardness and softness, are of resistance.' - Lyall, p.48. Therefore, from the original list or primary qualities - extension, divisibility, solidity or fluidity, hardness or softness, and figure, we are now down to just two - extension and resistance. At least this new qualification should satisfy Lyall. After all, how much further can he go? But he does not stop even here. 'Dr. Brown has reduced the primary qualities to these two. They may be reduced still further, viz., to resistance, for extension is rather a propriety of space than that of matter.' - Lyall, p. 48. This is Lyall's manner of presentation. As it can be seen, a great deal of attention is required in order to get the correct position that he maintains.

In analyzing Lyall's philosophy Armour/Trott consider that his ideas were not consistent enough to give birth to an original philosophy. There are different themes that Lyall uses, themes which can easily be found circulating in the philosophical preoccupations of the time, but there is nothing special emerging from this conglomerate. In Armour/Trott's eyes, Lyall is

“...a mechanist about the physical world. His preliminary analysis of first order objects and emotions suggests a contemporary mechanical stimulus-response model. But somewhere, on his view, mechanism stops short. He is a Platonist about the intellect. Intellect represents order, eternal principle and the transcendence of the shadow world of space and time. But these two worlds are separated by a gulf which he realizes must be bridged, at least at the level of descriptive psychology. The austere and otherworldly intellect must be brought into contact with the mechanical world. It is here that the secondary objects of emotions, that emotion as the background of the intellect and the object of its attention, come into play. But what causal relations ultimately hold here? Lyall draws upon the Augustinian model. Causation here is in terms of objects sought and avoided, a feeling of benevolence, and the feeling of self-satisfaction. But all this cannot simply be a chaos of conflicting poles, for action does result. Thus he introduces the Augustinian notion of love as the final formulation of direction.” (Armour/Trott, p. 83)

This way, Lyall seems to be more of an eclectic than an original philosopher. If we take Armour/Trott's conclusions to be true, then Lyall is a Canadian philosopher only in name. He did not produce anything which can be taken into consideration as Canadian. Therefore, he might as well have written the same things back in Scotland.

But, the inconsistencies which are discovered following Lyall's arguments and ideas can have another explanation: this would be that Lyall's background as an idealist, which was developed during his 
studies in Scotland, was confronted and had to stand up to and explain the nature (as it exists in Canada, as opposed to Scotland) which cannot be avoided and which makes itself present all the time in the most obvious way. Reading the first part of the Intellect, the Emotions and the Moral Nature, one can be surprised by the struggle Lyall goes through in the attempt to explain how sensation becomes knowledge, how reality becomes idea. And this makes me think that he would not give up easily when it comes to the actual existence of the physical world. But, he cannot concede to materialism, because materialism is "the proper spawn of too great an engrossment in mere matter, whether it be in the too exclusive devotion to the business and pursuit of life, or too entire an attention to the physical and mechanical sciences”. (Lyall, p. 89)

Also, he does not subscribe completely to idealist views either, because he speaks all the time about the world outside and the existence of both sensation and intellect. "It is a marvelous connexion which exists between the world without and the world within” (Lyall, p. 102). The mind cannot work without the data which sensation provides to it. There are places in the first third of the Intellect..., where he can be perceived as nothing else but a mind/body dualist and not an idealist at all. "Mind and matter are the two substances about which all philosophy is conversant. These two substances may be said to divide the universe.' (Lyall, p.13) Moreover, he repeatedly states that:

"Mind cannot be an organic result. True, sensation is partly material and the difficulty of deciding where the material part of the process or phenomenon stops, and the mental part begins, may be urged in favor of materialism; but sensation is not all the phenomena of mind, and while we confess a difficulty, we still mark the total difference between a material and a mental product.” (Lyall, p.92)

Now, what Lyall affirms is that the world, as our intellect perceives it, is just the world of material objects. The intellect provides us with scientific knowledge which develops on the presupposition that there is a material world. But, remember his manner of presentation? He does not stop here. He assumes and acknowledges the implications of his statements but then he proclaims that the intellect is not the only source for knowledge. There is something else that also contributes to our understanding of the world. This is what makes him an idealist but not of the German kind nor of the kind professed by Berkeley. What I am talking about here is another sort of reason - practical reason. Thus, Lyall's idealism fits within the framework of what Canadian idealism denominates. And Canadian idealism has as its most important particularity the search for a balance in the use of reason and emotion, or as it was termed - the accommodationist use of reason, which is nothing else but the thesis which sustains the whole essay on Canadian philosophy and culture written by Armour/Trott. Practical reason is what completes our interaction with the world. It refers to our moral nature and to our emotions. Unlike the intellect, the knowledge gained through the use of practical reason is indubitable and reveals to us our true nature as moral agents and our obligations to others. 
"There is a practical power in the sentiment. It has an authoritative voice within us which makes us feel our relation to being, and such relations as we dare not disregard. It is here that consciousness cannot be mistaken. There can be no discussion about the truthfulness of its intimations. The feeling within now is such that no dubiety rests upon it; it is practical, overwhelming. There is reality here if nowhere else. We have got out of the world of shadows into the world of realities - of mere consciousness into authoritative consciousness which speaks aloud, which enforces itself, which does not admit for a moment of questioning, which will not allow debate or parleying, which unites us in relations not to be broken with our fellow-beings, while it makes us realize to ourselves our own substantive existence and importance.” (Lyall, p.469)

After writing almost three hundred pages on the intellect and its functions, Lyall goes further and analyzes the emotions. He recognizes the importance of the intellect in the process of acquiring knowledge but he still thinks that there are some areas where the intellect is useless. It presents us with a picture of reality which is not different from the one Plato offers in the Cave myth. The phenomenal reality has the same constitution as the shadows on the walls of the Cave.

"The intellectual part of our nature is a surpassing mystery - those processes by which the mind becomes all light, opens to idea of itself and the outer world of the universe, puts upon all that is external or internal its forms, while these forms have their counterpart without, or in the inner self, constructs science, and makes its own processes the subject of its investigation - but marvelous as this is, there are mysteries of our nature far greater than these and the intellectual part may be said to be the least wonderful of our compound being." (Lyall, p. 279)

Thus, the intellect loses its glamour and this is because the emotions come onto the scene. Without them, human beings would not be capable of action and actions are those which make us what we really are. "Emotion is a higher state than pure intellect", he writes (Lyall, p. 284). This is a serious affirmation and it has implications in the theory of moral nature. Prima facie, it looks as if he is going in the same direction as Hume on this. "The emotion is the state or feeling of the mind apart from its source....and...what is moral, is the possession of the emotion, not the emotion itself."(Lyall, p. 285). Putting this face to face with the moral action, Lyall seems to reach conclusions very close to those of Hume. He says that the mind can, without a shade of doubt, recognize a distinction between rightness and wrongness. It does that with the same easiness as it does when it has to distinguish between, say - two categories, or two numbers. But things get complicated when the question 'why?' arises. “Can we explain why it is right, or why it is wrong - give any reasons for pronouncing it so? Now, it would seem that no account or explanation of this can be given, but that we perceive at once the quality of rightness or wrongness apart from any such explanation...”(Lyall, p. 487). Does not this sound like Hume's account of morality? 
After all, Hume is giving a lot of credit to emotions too. In his 'Treatise on Human Nature' he argues that the role of reason in moral decisions is very limited and that moral approval is only a feeling in the mind of the person that makes a moral judgment. "Actions, he says, may be laudable or blamable, but they cannot be reasonable or unreasonable". (David Hume, A Treatise of Human Nature, p. 458) There are several arguments which are brought forth to sustain his position. The first one would be that reason involves only judgments about reality, but when one examines the content of a moral action, one does not have to deal with a fact. The only thing that is there is just a feeling. Moreover, moral pronouncements are closer to our way of experiencing aesthetic pronouncements which are feelings and they are nowhere close to rational judgments.

One could think that moral pronouncements develop in a similar manner to those of logical and mathematical reasoning. But Hume argues that while in the latter disciplines we begin with known facts and discover a new, unknown fact, in the disciplines of the first category, all the relevant facts must be known from the beginning.

Besides, moral actions are done with the sole purpose of happiness and, as far as the happiness is involved, reason has to step aside. "Morality, therefore, is more properly felt than judged of; though this feeling or sentiment is commonly so soft and gentle that we are apt to confound it with an idea, according to our common custom of taking all things for the same, which have any near resemblance to each other.”(Hume, p. 470) This is a rough account of what Hume has to say with regard to this subject. But it does not fit exactly in Lyall's framework. Towards the end of the second chapter of his work, where he is talking about emotions, he notes : "Man is not only a mere being, he is a moral being; has not only a place in creation, but has a part to perform in creation: he not only lives, and thinks, and feels - he wills - and not only wills, but wills according to a law of right and wrong. And this law is not arbitrary, it is eternal; it is not imposed, it is a part of his very nature. It belongs to every moral being, enters into the essence of a moral constitution. It is the law of duty, the law of right and wrong, a law of eternal and abstract propriety.”(Lyall, p. 468) This time, it seems that Lyall moves a long way apart from Hume.

But, let us not forget Lyall's manner of presentation: he states a position (even though he does not say clearly that this particular position is Hume's) and then, he qualifies it. But he does not stop there -he qualifies it again. And for this he is 'talking' with Kant and his ideas about moral duty which arises out of the reverence for law. He goes further in analyzing the meaning of the word 'reverence' and how it is connected with the concept of 'duty' and that of 'law'. For Kant, an action performed out of duty "has to be done irrespective of all appetite whatsoever”. Virtue is deprived of any trace of feeling and it is subjected to the law. But, “... what I apprehend to be my law, I recognize to be so with reverence, which word denotes merely the consciousness of the immediate, unconditional, and unreserved subordination of my will to the law. The immediate determination of the will by the law, and the consciousness of it, is called reverence, and is regarded not as the cause but as the effect of the law upon the person”. (Lyall, p. 509) This is Kant's position 
and, after what happened with Lyall's impact on Hume's position, one might think that this will satisfy him. But no luck this time either! Kant is wrong too. Why?

Lyall accuses him of not admitting love to be a part of reverence. His almost instinctive reaction is to think that in all reverence there must be a certain degree of love, otherwise the reverence would be 'mere fear". "It would seem to be necessary, in order to moral approbation being real, that there should be love as well as reverence for the law: it would be otherwise a distant reverence, not approval: there would be assent to the rightness of the law, not approbation. Distant reverence is at most a cold feeling, and it is not properly approbation till there is love.” (Lyall, p. 510)

Lyall emphasizes greatly the concept of love. Love is the most essential feeling, love is the feeling which connects us to the other, love is that which discovers a being for us. Love, next to sympathy, benevolence and gratitude, is part of the emotions which 'terminate on being'. "An event produces joy, an object awakeness our delight; but the object of love is the object of our love. We love the object.”(Lyall, p. 391) When speaking of love, Lyall is not trying to give an explanation of this concept with respect to the intellectual understanding of it but following the implications that love has on action. Love has as its object the being. Hence, there can be talk about love not only with regard to fellow humans or God but also there can be love for nature and everything that pertains to nature. The only difference is that love increases proportionally with the purity of its object. Love of God is the absolute on the scale of which Lyall is thinking. "Moral and intellectual qualities give an immense increase to emotions”, he writes. (Lyall, p. 410). Moreover, “...we know that inanimate objects even may awaken our love, a kind of attachment, and this may be distinguished from the delight or pleasure which they give us; the one is delight in the object, the other is delight produced by the object. The former, then, is just love; and to say that love is delight in an object, or in the contemplation of that object, is to describe the emotion by itself.” (Lyall, p.392)

Thus, emotions (and, particularly, the emotion of love) complete our 'interaction' with what we call "the real". The intellect could not go further than scientific understanding. But Lyall sensed that there is something left and only the emotions could connect us with it. Pure reason has to work together with practical reason in order to give us the complete picture of reality. Why? Because practical reason, unlike pure reason, has direct access to the real and it is indubitable since it refers to the very being of what exists in nature, of another human or of God.

“The emotion of love is a source of knowledge. Nature herself 'is animated, intelligent, full of sentiment'. This is the idealistic insight concealed from us by our narrow reliance on the intellect as our source of knowledge. Yet for Lyall the intellect is still important. It too is a source of knowledge. He devotes the first third of the book to it and to the characteristics of the material world it reveals. Unlike the Romantic poets or other ethical idealists, Lyall's idealism neither ignores nor diminishes as unimportant the findings of science.” (J.D.Rabb - Canadian Philosophy at Lakehead). 
We have seen that Lyall rejects the kind of idealism which stems from Berkeley's ideas. Roughly speaking, for Berkeley, the only thing that exists and that we are certain of is the mind. But this does not sound well for Lyall. He could have criticized him by following either Hume (and consequently, fall into skepticism) or Kant (but he rejects part of Kant's ideas also). How can his position be explained? The thing which might explain it is that Lyall became aware of the importance of nature. His stay in Canada must have influenced him. He wants to say that, doubtless, Berkeley was wrong. Nature exists! Physical objects exist! And this is what Lyall does. He finds out that the power of the intellect is limited but he does not desert the post. In order to have that piece of knowledge the mind needs but cannot get through the intellect, Lyall requests help from the emotions. Emotions can give us knowledge about the world. Love is the emotion which unveils the being. Certainly, this will sound very strange for Berkeley and it would be strange for Kant as well. Hume would not expect this turning point also. But it seems natural to Lyall.

This is the point I wanted to make here. William Lyall's work is not just a patch-quilt of foreign ideas (as Armour/Trott state). It is original and it is original in a Canadian way. "His work is a splendid example of what Armour and Trott have called the accomodationist use of reason, of philosophical federalism.” (J.D.Rabb - Canadian Philosophy at Lakehead). I am not saying though that he already put a mark on the philosophical Pantheon of ideas but he, most certainly, realized that in order to do philosophy (at least in that part of the world), one must have open not only a rational eye, but an emotional eye as well. The only thing which Lyall lacks in his affirmations and in the formulation of his ideas is confidence. The silent echo of an non-existent tradition springs through the chasms of the chapters of his work. He was an exile. He was supposed to feel at home, but he did not. He could not. His (philosophical) home was overseas. Instead, he was in Canada trying to build his own shelter. He knew how to do it but he had to do it making use of what he was offered there. And that was nature...

"In so far as Lyall's idealism is concerned what is important, indeed crucial, is his claim, not merely that we can sympathize with nature, but rather that the emotion of sympathy can actually animate nature. Here he begins to sound more like a romantic poet than a rationalist philosopher: ‘ There is something in the voice of a brook which stirs the innermost emotions of the soul, placid, steady, deep; in the sigh of the wind; in the dash of the ocean; in the sunshine and gloom; in calm and tempest: our mind feels in all, has an emotion corresponding to each. Such is the law, such is the power of sympathy. What power does it exert in uniting society! What a bond of connection! What an amalgamating principle! And through it nature itself is animated, intelligent, full of sentiment, and the inspirer of the finest, and the most delightful, sometimes the most exalted emotions.' - Intellect, Emotions and the Human Nature, p.461-462.” (J.D.Rabb - Canadian Philosophy at Lakehead) 
Lyall's development of ideas takes place abruptly. There is not a smooth flow of philosophical thought. He tries to set new views, but he does that in as an yet un-explored territory. The school he comes from, continental philosophy, enjoys the richness of a tradition (a thing which did not exist in Canada, but whose existence was felt necessary). A tradition cannot come into being using borrowed elements but using its own resources. And a tradition is necessary because without it nothing can be labeled as new, if there is no other term to which it can be compared. For Lyall, to use the language and the concepts of Western philosophy seems a seductive attitude. But they do not work any longer since the given of analysis has changed. And this explains the aura of eclecticism surrounding Lyall's work. A certain philosophical tradition can only be reached when it gets to the point of finding a particular, new form of communication. It finds its own identity when it develops a more free and efficient means of relating to the other traditions. It is only then when (detached, almost in a ludic manner) thought can follow its essential and natural questions. 


\section{Bibliography:}

1. Armour, Leslie \& Trott, Elizabeth - The Faces of Reason - An Essay on Philosophy and Culture in English Canada 1850-1950, Wilfrid Laurier University Press, Waterloo, Canada, 1981

2. Hume, David - A treatise of Human Nature, Oxford, GB, 1967

3. Kant, Immanuel - Groundwork of the Metaphysics of Morals, (trans. H.J.Paton) Harper \& Row, Publishers, New York and Evanston, 1964

4. Kant, Immanuel - The Critique of Judgment, (trans. J.C. Meredith), Oxford at The Clarendon Press, GB, 1969

5. Lyall, William - Intellect, The Emotions and The Moral Nature, Edinburgh: Thomas Constable and Co.; London: Hamilton, Adams and Co., 1855

6. McCosh, James - The Scottish Philosophy, London, MacMillan and Co, GB, 1875

8. Rabb, J.D. (editor) - Religion and Reason: A Symposium, Frye Publishing, Winnipeg, Canada, 1983

9. Rabb, J. D. - Canadian Philosophy at Lakehead: The Silver Jubilee Lecture in Philosophy 